Doi: $\underline{\text { dx.doi.org/10.17921/2525-5320.2016.134-143 }}$

\title{
O ENSINO DE ENFERMAGEM: UMA REVISÃO BIBLIOGRÁFICA
}

\author{
Maicon Depieri* - UNOPAR
}

Bernadete de Lourdes Streisky Strang* - UNOPAR

Palavras chaves: Ensino. Enfermagem. Ciência.

\section{INTRODUÇÃO}

Quando falamos em um curso de graduação em Enfermagem este deve estar inserido em um espaço permanente de inovação, onde a aprendizagem, o ensino, a atualização do projeto pedagógico, o perfil do profissional, as competências e habilidades, os conteúdos (conceituais, procedimentais e atitudinais), as disciplinas (unidades curriculares, temas e conteúdos), as matrizes curriculares, as metodologias de ensino, as atividades de aprendizagem, o processo de avaliação e a extensão, encontrem espaços para discussões e, consequentemente, revisão de paradigmas, mudança de modelos mentais e de hábitos e culturas.

O fator decisivo dessa revolução consiste na importância de se programar o futuro por meio de um novo modo de fazer ciência, que se vale da informação, que formula problemas e propõe soluções sem se deixar enredar previamente por seus vínculos. O conhecimento e a tecnologia assumem, portanto, um papel central na nova sociedade; no plano social, na empregabilidade. Dessa forma, o egresso que deseja ser dono do seu futuro, ter sucesso pessoal ou profissional e ter empregabilidade deve apropriar-se do saber, deve ter conhecimento e elevados padrões de conduta ética, moral e estética. Tal pratica pode ser confirmado por Waldow (2005, p.16).

\footnotetext{
A estética induz explorar questões que surgem quando as pessoas se tornam auto reflexivas acerca de seu envolvimento com formas de arte. É possível querer saber, ter curiosidades acerca do prazer, assim como da dor que as coisas nos provocam, despertando percepções sobre a beleza, sobre o horror, sobre a harmonia, assim como sobre a desigualdade.
}

Os processos educativos buscam a passagem do estado de desconhecimento

\footnotetext{
*E-mail: maicon.depieri@kroton.com.br

*E-mail: bernadete.strang@gmail.com
} 
relativo para um estado de conhecimento capaz de transformar a realidade, no processo de graduação em enfermagem essa prática não e diferente, pelo contrário, muitas vezes o aluno que ingressa em um curso de graduação em muitas vezes jamais havia tido contato com os estudos que ora se inicia. Dessa forma, fica claro que na educação, é necessário considerar o contexto do indivíduo e do meio em que ele vive.

Por esse motivo, para formar um profissional na área da enfermagem, muitas tem sido as discussões e preocupações por parte de estudiosos da área ao longo da história da enfermagem brasileira. Essa mesma preocupação frequentemente é alvo de pronunciamentos dos representantes das entidades de classe em eventos e publicações. No meio acadêmico não tem sido diferente, ou seja, no âmbito das instituições, essas inquietações passam por discussões entre grupos de docentes e discentes dos cursos de graduação e pós-graduação, preocupando sempre com o egresso (DANTAS, 1999).

O significado da educação enquanto processo social extrapola a educação formal, aqui considerada a educação ocorrida em instituições oficiais de todos os níveis, pois necessita de sistematização para instrumentalizar indivíduos.

O objetivo do presente estudo é identificar as inovações acerca do ensino de enfermagem no brasil na última década.

\section{MATERIAL E MÉTODOS}

A metodologia utilizada foi a revisão bibliográfica, para tanto utilizou-se publicações nas bases de dados Lilacs, Biereme, BVS, Scielo disponíveis na internet no ultimo decênio bem como em livros da área da saúde que abordassem o ensino de enfermagem, a pesquisa ocorreu entre os meses de fevereiro a julho do corrente ano, encontrou-se 21 artigos que abordasse a temática o ensino em enfermagem e três livros impressos.

\section{RESULTADOS E DISCUSSÃO}

\section{Histórico acerca do ensino em enfermagem no Brasil}

O ensino de Enfermagem no Brasil iniciou oficialmente em 1890, com a promulgação do Decreto n.791, tendo como objetivo preparar enfermeiros e enfermeiras para trabalhar nos hospícios e hospitais civis e militares, nos moldes da escola existente em Salpetrière, na França. O Hospital Nacional dos Alienados havia 
passado para controle direto do novo Governo Republicano e diante da necessidade da capacitação de pessoal para realizar os cuidados de enfermagem, foi criada a Escola Alfredo Pinto, no mesmo ano, dirigida por médicos, que também supervisionavam o ensino. Sua existência, porém, foi ignorada por Jane A. Jackson que, representando o Brasil na reunião do Conselho Internacional de Enfermeiras (ICN) realizada em 1901, não mencionou a existência dessa escola. Isso talvez explique o fato da Escola de Enfermagem Anna Nery ser considerada a primeira escola de enfermagem no Brasil (PAIVA et al., 1999).

Mais tarde em 1916, cria-se a Escola Prática de Enfermeiras da Cruz Vermelha Brasileira para treinar socorristas voluntários e, em 1920, na mesma escola, foi criado o curso de visitadoras sanitárias (PAIVA et al., 1999).

A formação de visitadoras sanitárias precede a institucionalização da enfermagem, tanto na Europa, quanto nos Estados Unidos e no Brasil. Nas atividades destas visitadoras repousam as raízes da Enfermagem em Saúde Coletiva [...] (SALUM; BERTOLOZZI; OLIVEIRA, 1999).

Nesse contexto considera-se que a Enfermagem Moderna foi introduzida no Brasil em 1923, mediante a organização do serviço de enfermeiras do Departamento Nacional de Saúde Pública (DNSP), então dirigido pelo médico sanitarista Carlos Chagas. O ensino sistematizado tinha como propósito formar profissionais que garantissem o saneamento urbano, condição necessária à continuidade do comércio internacional principalmente nos portos, que se encontrava ameaçado pelas epidemias. Essa capacitação estava a cargo de enfermeiras da Fundação Rockfeller, enviadas ao Brasil com o intuito de organizar o serviço de enfermagem de saúde pública e dirigir uma escola de enfermagem. Esta foi criada em 1922, mas iniciou seu funcionamento em 1923, com o nome de Escola de Enfermagem do DNSP. Em 1926, passou a ser designada Escola de Enfermagem Anna Nery (EEAN) e, em 1931, Escola de Enfermagem da Universidade Federal do Rio de Janeiro (GALLEGUILLOS, OLIVEIRA, 2001).

\section{A Lei de Diretrizes e Bases - LDB do ensino e as diretrizes para o ensino de enfermagem}

O ensino de enfermagem, assim como o ensino de outras profissões, busca a construção do conhecimento cientifico ao mesmo tempo em que desenvolve à consciência crítica do aluno, considerando todos os aspectos de ensino, tanto o 
formal como também o conhecimento empírico trazido pelo acadêmico por meio de sua existência (PERES, 2002).

Historicamente a enfermagem era tida como uma arte (a arte de cuidar), hoje a enfermagem é considerada como uma ciência, e como ciência se faz necessário a aplicabilidade por parte dos professores conteúdos embasados em evidencias cientificas. Em 23 de dezembro de 1996, foi publicada no Diário Oficial da União a nova Lei de Diretrizes e Bases da Educação (LDB), Lei n.9.394 de 20 de dezembro de 1996 que, repetindo o texto da Constituição Federal, reiterou a perspectiva vigente que atribui a responsabilidade da educação à família e ao Estado, já contida na LDB de 1961.

Para Belloni (1997) do ponto de vista da educação superior, essa reforçou a atual tendência profissionalizante, bastante questionada, na qual a formação global é escassamente considerada.

Em julho de 1999, a proposta sobre as Diretrizes do Ensino de Enfermagem, pautada tanto nos documentos encaminhados pelas IES e pela ABEn - Associação Brasileira de Enfermagem, em conformidade com o "Modelo de Enquadramento das Propostas de Diretrizes Curriculares" formulado pelo Departamento de Políticas de Ensino Superior - SESu/ MEC, postulou:

a constituição da estrutura do curso deverá garantir os princípios de autonomia institucional, de flexibilidade (incluindo as disciplinas obrigatórias e optativas) e pluralidade no currículo assim como a possibilidade de opção do corpo discente. Deve haver no currículo a possibilidade de opção por conteúdos que gerem competências específicas(habilitações) nas seguintes grandes áreas de formação: bacharel, formação aplicada profissional, formação de docentes e formação de pesquisadores perfazendo um mínimo de 500 horas por habilitação.

As universidades deveriam compor um curso respeitando o mínimo de 4.000 horas-aula e oito semestres letivos. O estágio curricular deveria ser no mínimo de 500 horas, sob coordenação docente e contando com a participação de enfermeiros dos serviços de saúde. O estágio curricular não deveria substituir o ensino clínico, previsto como atividade complementar. A proposta privilegiava a formação do enfermeiro crítico e reflexivo com competência técnico-científico-ético político-socialeducativa (BRASIL,1999).

O professor de enfermagem tem a disposição conteúdos científicos disponíveis em livros e em artigos indexados em bases de dados, esse por vezes faz publicação 
de artigos científicos, participar de congressos. Todavia, tão importante quanto esses fatores é o fato do professor ter uma formação didática desenvolvido. Com essa junção de para saberes o mesmo proporcionará o processo ensino aprendizagem.

Tardif e Raymond (2000), aborda em sua obra Saberes, tempo e aprendizagem do trabalho no magistério, a respeito dos saberes dos professores, destaca-se os saberes mobilizados e empregados na prática cotidiana, saberes esses que dela se originam e que servem para dar sentido às situações de trabalho que thes são próprias.

O ensino de enfermagem no país passou por várias fases de desenvolvimento ao longo dos anos, tendo como reflexo de cada mudança o contexto histórico da enfermagem e da sociedade brasileira. Consequentemente, o perfil de enfermeiros apresenta significativas mudanças em decorrência das transformações no quadro político, econômico e social da educação e da saúde no Brasil e no mundo (ITO et al, 2006).

Em meados de 1980, observa-se que foi intensificado as discussões acerca do processo de formação do profissional enfermeiro. No final de 1994, o Ministério da Educação e do Desporto, através da Portaria 1721 (de 15 de dezembro de 1994), atendendo às expectativas políticas da saúde voltadas para a atenção primária, propôs a mudança no chamado currículo mínimo de enfermagem cujo foco era um ensino precário, enfatizando a formação de um profissional "generalista", ou seja, com visão holística para atuar nas áreas de assistência, gerência, ensino e pesquisa (CHIRELLI, 2002).

Essa formação generalista implicava na competência técnico, científica e política decorrente de uma reflexão crítica acerca do homem na sociedade, do processo saúde-doença, a partir de abordagem multidisciplinar e no saber próprio da enfermagem, com ênfase nos aspectos administrativos desenvolvidos nos serviços de saúde (FREITAS, 1993).

\section{A pesquisa em enfermagem}

Para Silva e Fernandes et al. (2010) é natural que em pleno século XXI, e de acordo com as inovações das configurações do mundo globalizado e seu acelerado processo de modernização científica e tecnológica, se faz necessário novas formas de construção do conhecimento, pressionando mudanças no processo de formação 
de profissionais, esses devem ser dotados de habilidades e competências para o atendimento sistematizado e na integra à saúde da população que necessita desse suporte técnico e científico.

A Lei de Diretrizes e Bases da Educação Nacional - LDB (ME, 1996) fundamenta o processo de formação na educação superior através do desenvolvimento de competências e habilidades; do aperfeiçoamento cultural, técnico e científico do cidadão, da flexibilização dos currículos, da implementação de Projetos Pedagógicos de Cursos que vão de encontro com as necessidades dos acadêmicos, bem como da demanda de pacientes que esses atenderam durante e após o graduação em Enfermagem, numa perspectiva de mudança para a formação profissional (M. E, 1996).

Fernandes (2005), aponta que essas premissas apontam novas configurações para os padrões curriculares, até então vigentes, indicando a necessidade de uma reestruturação dos cursos de graduação com mudanças paradigmáticas no contexto acadêmico, direcionando a construção de Diretrizes Curriculares para cada Curso de Graduação, com foco no perfil do egresso.

Em atendimento à LDB, foi aprovada a Resolução CNE/CES No 03 de 7/11/2001 que definiu as Diretrizes Curriculares Nacionais para o Curso de Graduação em Enfermagem (DCN/ENF), explicitando a necessidade do compromisso com princípios da Reforma Sanitária Brasileira e do Sistema Único de Saúde (SUS), definem os princípios fundamentais para a formação de profissionais críticos, reflexivos, inseridos no contexto histórico-social, pautados em princípios éticos e capazes de intervirem nos problemas da atenção à saúde, onde se insere a atenção à saúde da população (ME, 2001).

Nesse contexto, o processo ensino aprendizagem cientifico, devem ir de encontro com a realidade que o acadêmico está inserido.

A aplicabilidade de conteúdo fracionados e simplificados, vem prevalecendo na formação do profissional enfermeiro, hoje em dia para o atingimento das habilidades e competências do egresso destaca-se a pratica constante de atividades onde o graduando possa associar a teoria com a prática.

No entanto trazer os conhecimentos empíricos para sala de aula também tem se tornado uma prática bastante comum e eficaz, onde por meio de uma curiosidade trazida por um discente, os demais alunos iniciam uma discussão pertinente acerca da temática e nesse momento o professor se apresenta como um mediador desse 
processo inserindo a medida que a discussão aconteça argumentos técnicos e científicos, amparados na literatura e em pesquisa que comprove a fidedignidade de tais argumentações.

Para que tal ação aconteça é mister que o professor tenha uma pratica pedagógica que o permita lidar com tal situação, ou seja, querer realizar tal dinamização em sala de aula requer um preparo prévio, bem como um conhecimento acerca da gestão de sala de aula e mais do que isso o domínio do conteúdo ora ministrado. Por isso a prática pedagógica deve ser uma prioridade nos enfermeiros que atuam como docentes nos cursos de graduação em enfermagem.

Observa-se que a maioria das instituições universitárias brasileiras adotam, o modelo da pedagogia tradicional. Essa tendência pedagógica segundo (LUCKESI 1994; FREIRE 2001) centra-se não só na exposição do conhecimento pelo professor e na passividade com que os educandos o recebem, mas na desarticulação existente dos conteúdos e procedimentos relacionados com o cotidiano e a realidade social no qual os alunos estão inseridos.

Dessa forma, torna-se difícil para os acadêmicos entender a função transformadora dos conhecimentos adquiridos, já que esses são transmitidos para serem na maioria das vezes memorizados para uma prova ou questionamento futuro. Para o aprendizado efetivo, é necessário que percebam a relevância do que Ihes está sendo ensinado e sejam capazes de aplicá-lo durante sua pratica enquanto profissionais (CORLETT, 2000).

Destaca-se nesse contexto que a partir do momento que as instituições de ensino valorizam as atitudes humanitárias, considerando a importância da busca do autoconhecimento, tanto para os professores como para os estudantes, em qualquer momento do aprendizado teórico ou prático, estão valorizando as dimensões afetivas e sociais que integram essas pessoas na sua totalidade. Essa valorização do desenvolvimento global e holístico é tão importante quanto a dimensão intelectual ou cognitiva do processo ensino-aprendizagem, ainda tão presente nos dias atuais (LUCKESI, 1994).

\section{CONCLUSÃO}

Percebe-se com essa pesquisa de revisão bibliográfica que o predomínio de práticas pedagógicas tradicionais, ou seja, aquelas em que os alunos são ouvintes e os professores usam de uma aula expositiva para transmitir um conteúdo ainda 
estão muito presente nos docentes de enfermagem.

Moya (2006) afirma que esse conhecimento complexo, entretanto, é transmitido através de métodos de ensino tradicional, rígidos e mecânicos, não sendo oportunizado ao aluno condições de estabelecer relação com o ambiente que está inserido, impossibilitando o desenvolvimento do senso crítico e analítico.

Para que o processo de ensino-aprendizagem aconteça de forma agradável e eficiente, é necessário considerarmos aspectos de grande importância, entre eles o preparo do professor, este pode ser evidenciado por meio de seu empenho e dedicação nas atividades de ensino, bem como no engajamento para se manter atualizado nas disciplinas que leciona. Outro aspecto relevante para que o processo de aprendizagem aconteça está no fato do professor utilizar os recursos didáticos disponíveis, como leituras e discussões de artigos, textos, utilizar novas tecnologias em suas aulas. Por último e não menos importante o professor precisa ter uma boa gestão da sala de aula, onde essa seja um local onde a prática do ensino esteja favorável, como ambiente limpo, arejado, confortável com clima de respeito mútuo inclusive (WALDOW, 2005).

Decorrida quase uma década de aprovação das DCN/ENF em nosso país, observa-se avanços importantes, particularmente no que se refere à construção/reconstrução de Projetos Pedagógicos dos cursos de graduação em enfermagem. Porém muitos desafios ainda necessitam ser superados, visando à transformação do perfil dos futuros profissionais de saúde (LOPES, 2008).

Sobre o SUS - Sistema Único de Saúde, destaca-se que o profissional enfermeiro pode ser considerado como um dos sustentáculos do projeto do SUS, com destaque para sua atuação no campo das práticas, da docência e da pesquisa em Saúde Pública e Saúde Coletiva. A profissionalização é analisada na perspectiva da constituição de sujeitos profissionais, como coletivo que domina um saber técnico-científico específico, normalizado, legitimado do ponto de vista social e juridicamente sancionado, definido a priori, com delimitações mais ou menos claras a respeito do que o enfermeiro deve e pode fazer, numa concepção carregada de abstração e generalização.

Lessa (2002), afirma que uma perspectiva marxista, não se pode desvincular o trabalho de enfermagem das reais e concretas condições de produção e reprodução da existência. Num sentido teleológico, o que o trabalhador busca, como objetivo, já se expressa idealmente, em sua imaginação, desde o início, mas o resultado final 
dependerá também das condições concretas de produção do trabalho. A dimensão educativa foi sempre enfatizada no trabalho de enfermagem, mais até do que em outras profissões.

Ainda que o profissional enfermeiro seja visto como educador, a ação educativa tende a ser vista mais como uma ação técnica componente ou adicional ao conjunto de práticas profissionais, em lugar de uma dimensão inerente à prática profissional. Com frequência, esta dimensão é referida como mais uma atribuição do enfermeiro a ser incorporada no processo de trabalho, e tende a reproduzir a racionalidade biomédica hegemônica.

\section{REFERÊNCIAS}

ALMEIDA, C.C; ROCHA, S.M.M. O trabalho de enfermagem. São Paulo: Cortez; 1997.

BELLONI, I. A educação superior na nova LDB. In: BRZEZINSKI, I. (Org.) LDB interpretada: diversos olhares se intercruzam. São Paulo: Cortez, 1997. p.123-40.

BRASIL, M.E. Secretaria de Educação Superior. Departamento de Política de Ensino Superior. Coordenação das Comissões de Especialistas de Ensino. Comissão de Especialistas de Enfermagem. Diretrizes Curriculares para os Cursos de Graduação de Enfermagem. Brasília, 1999.

BRASIL, Ministério da Educação. Lei No 9.394 em 20 de dezembro de 1996: estabelece as diretrizes e bases da educação nacional. Diário Oficial da União, Brasília (DF) 1996 dez 23; 34 (248) Seção 1:27,.p.833-41.

BRASIL, M. E. Conselho Nacional de Educação. Câmara de Educação Superior. Resolução CNE/CES No 3 de 7 de novembro de 2001: Diretrizes Curriculares Nacionais do Curso de Graduação em Enfermagem. Brasília, 2001.

CECCIM, R.B; FEUERWERKER, L.C.M. Mudança na graduação das profissões de saúde sob o eixo da integralidade. Cad. Saúde Pública, v.20, n.5, p.1400-1410, 2004.

CORLETT, J. The perceptions of nurse teachers, student nurses and preceptors of the theory-practice gap in nurse education. Nurse Educ Today, v.20, p.499-505, 2000.

DANTAS, R.A.S; AGUILAR, O.M. O ensino médio e o exercício profissional no contexto da enfermagem brasileira. Rev. Latinoam. Enferm., v.7, n.2, p.25-32, 1999.

DEMO, P. Pesquisa e construção do conhecimento: metodologia científica no caminho de Habermas. Rio de Janeiro: Tempo Brasileiro, 1994.

FERNANDES, J.D. et. al. Diretrizes Curriculares e estratégias para implantação de uma nova proposta pedagógica. Rev. Esc. Enferm. USP, v.39, n.4, p.443-449, 2005. 
FREITAS, D.M.V; FÁVERO, N; SCATENA, M.C.M. O ensino de graduação na Escola de Enfermagem de Ribeirão Preto da USP: suas perspectivas. Rev. Latinoam. Enferm., v.1, v.esp. p.25-34, 1993.

FREIRE P. Educação e mudança. Rio de Janeiro: Paz e Terra; 2001.

GALLEGUILLOS, T.G.B; OLIVEIRA, M.A.C. A gênese e o desenvolvimento histórico do ensino de enfermagem no Brasil. Rev. Esc. Enf. USP, v.35, n.1, p.80-87, 2001.

ITO, E.M. et al. O ensino de enfermagem e as diretrizes curriculares nacionais: utopia x realidade. Rev. Esc. Enferm. USP, 2006.

LESSA, S. Mundo dos homens: trabalho e ser social. São Paulo: Bomtempo, 2002.

LOPES, D. N. et al. Um olhar sobre as avaliações dos cursos de graduação em enfermagem. Rev. Bras. Enferm., v.61, n.1, p.46-53, 2008.

LUCKESI, C.C. Filosofia da educação. São Paulo: Cortez, 1994.

MOYA, J.L.M.; ESTEBAN, M.P.S. La complejidad del cuidado y el cuidado de la complejidad: un tránsito pedagógico de los reduccionismos fragmentantes a las lógicas no líneales de la complejidad. Texto Contexto Enferm., v.15, n.2, p.312-319, 2006.

PAIVA, M.S. et al. Enfermagem brasileira: contribuição da ABEn. Brasília, ABEn Nacíonal, 1999.

PERES, A.M. Sistema de informações sobre pesquisa em enfermagem: proposta para um departamento de ensino de universidade pública. Florianópolis: Centro Sócio-Econômico da UFSC, 2002.

SALUM, M.J.L; BERTOLOZZI, M.R; OLIVEIRA, M.A.C. O coletivo como objeto da Enfermagem: continuidades e descontinuidades da história. Washington: Organización Panamericana de La Salud, 1999.

SILVA, M.G. et al. O Processo de formação da(o) enfermeira(o) na contemporaneidade: desafios e perspectivas. Enferm., v.19, n.1, 2010.

TARDIF, M; RAYMOND, D. Saberes, tempo e aprendizagem do trabalho no magistério. Educ. Soc., v.21, n.209, 2000.

WALDOW, V.R. Estratégia de ensino na enfermagem: enfoque no cuidado e no pensamento crítico. Petrópolis: Vozes, 2005. 